\title{
Dosage Form Category
}

National Cancer Institute

\section{Source}

National Cancer Institute. Dosage Form Category. NCI Thesaurus. Code C84267.

A classification scheme to categorize dosage forms. 